\title{
Discussion on Combination of Contemporary Chu Opera and Music Teaching in Local Universities
}

\author{
Shuanghong Jiao $^{1, \text { a }}$ \\ ${ }^{1}$ Department of Music, Hankou college, wuhan 430212, China \\ ajjjsh@126.com
}

\begin{abstract}
Keywords: Contemporary Chu opera; Local Universities; Music teaching; Combination.
Abstract. With the five thousand years of civilization, China has accumulated a great deal of traditional culture. Chu Opera, as a typical kind of traditional dramas, has developed a sound musical system in the long stretches of history. While due to various factors, fewer and fewer people know about Chu opera. As we all known, universities are the major subjects inheriting and carrying forward traditional culture, thus, it is meaningful to integrate contemporary Chu opera into teaching of music classes in local universities so as to promote cultivation of more professional talents and lay a solid foundation for inheritance of Chu opera musical culture. From the perspective of origination and artistic features of Chu opera,this paper gives an analysis of the limitations in development of Chu opera and finally, and finally probes into the combination of Chu opera and music teaching in local universities for the purpose of support to progress of China's local musical culture.
\end{abstract}

\section{Introduction}

There are dozens of local operas and each of them are characterized with unique form of performance, among which, Chu Opera is the most outstanding. However, with global economic integration,western music has gradually stepped into our country and exerted great influence on our traditional culture. Hence, it is of vital practical significance to strengthen application of Chu opera in music classes of local universities and can not only help us in further understanding of Chu opera but also in organic integration of the two so as to realize inheritance and innovation and even internationalization of Chu opera.

\section{Overview of Chu Opera}

Chu opera used to be one of the traditional local operas in Xiaogan and put forward by Fu Xinyi, a Han opera artist and it fully embodied great wisdom of ancient Chinese people and reflected the production and living activities of the people at at time. There were various ways of performance for Chu opera which was highly inclusive and integrated many different cultures.During development of Chu opera, many local actors such as Guan Xiaobin, Gao Yuelou and so on made themselves well-known[1].Main artistic features of Chu opera are as shown in Table 1. While, at present, Chu opera is faced with sharp decrease in the number of opera troupes,personnel aging and lack of lack worthy successors and other difficulties and in urgent need of support from relevant parties.

Table 1 Artistic Features of Chu Opera

\begin{tabular}{|l|l|}
\hline Artistic Features & Types \\
\hline Tune & Banqiang, Minor and high-pitched tune \\
\hline Role & Male character, female character \\
\hline Theme & $\begin{array}{l}\text { Military play, court play } \\
\text { Name of operas } \\
\text { monks }\end{array}$ \\
\hline
\end{tabular}




\section{Development History and Limitations of Chu Opera}

Table 2. Brief Summary of Chu Opera Development History

\begin{tabular}{|l|c|l|}
\hline Stage & Time & Representative Work and Troupe \\
\hline Tracing back & 1850 & Sihai Shengping Tower, Gonghe Shengping Tower \\
\hline Developmen & 1922 & $\begin{array}{c}\text { Dongyong Selling Himself to Bury His Father, Zhang } \\
\text { Chaozhong }\end{array}$ \\
\hline Prosperity & $\begin{array}{c}\text { After founding of } \\
\text { new China }\end{array}$ & $\begin{array}{l}\text { Wuhan Chu Opera Troupe, Yunmeng County Chu } \\
\text { Opera Troupe }\end{array}$ \\
\hline
\end{tabular}

3.1 Voice of Chu opera

Voice and music for voice are the inseparable basis for development of Chu opera. The music for voice in Chu opera was derived from by inspiration of dialect speech and folk music in Huangxiao and on this basis, the contemporaneity Chu opera now is well established after a series of adjustment. Due to plenty of dialects in Chu opera, there are obvious limitations throughout its transmission, such as more conjunct motions and less leaping motions in interval relations, which result from flattening of melodic curves to a large extent and weaker lyricism. Although some changes were made in Chu opera after it spread into Hankou, the weaker lyricism remain the same, which failed to meet the requirements in "operatic players happily singing together".

3.2 Music materials

By analysis of the systematic tune system of Chu opera, minor, Banqiang and high-pitched tune together constitute the integral Chu opera system. In performance, Banqiang style is used in most cases, such as Ya tune. And in terms of music creation, we have been using Ya tune till now, which is bad for sustainable development of Chu opera.

3.3 Music literature

Two methods are used for analysis of means of music creation: first, graft and transplant, which refers to nesting of Chu opera in original taste and flavor. Secondly, corresponding adjustment and optimization of the music basis of original Chu opera. But the neither of two methods is capable of bringing brand-new vitality to Chu opera[2]. The fundamental cause of the problem lies in lack of professional music talents who are capable of specific practice, which directly hinders reform and innovation of Chu opera.

\section{Combination of contemporary Chu opera and music classes in universities}

Universities are the main carriers for cultivation of music talents, thus, it is highly meaningful to combine Chu opera and music teaching, especially for universities in cultivation of more professional talents and promoting inheritance and development of Chu opera. To be specific, there are several feasible measures to realize such purpose:

4.1 To obtain in-depth understanding of value of folk music

As the main subjects in music teaching, teachers have a direct influence on quality of education in their concept of national culture. Therefore, it is necessary for teachers to strengthen study on value of folk music and hold a proper view on excellent music cultural resources in our country in a dialectical way to enhance students' sense of national pride. Meanwhile, outstanding music cultural resources introduction, exploration shall be introduced, explored and fully utilized in re-preparation of music textbooks to stress the importance of Chu opera in local music teaching. Besides, environment is of certain negative effect on cultivation of talents3]. On this basis, multiple measures shall be taken to create good atmosphere so as to enable students to feel the charm of Chu opera and develop strong interests in learning.

4.2 To widely collect music materials

With regards to music teaching in local universities, the essence of fundamental integration of Chu opera lies in collection of music materials widely. In practice, measures can be taken in two aspects: first, music subject; and the other, teaching reform. During the collection process, teachers take full account of teaching requirement and students'learning needs and realize complete combination of the two from the perspective of artistic features of Chu opera and lay a solid foundation for smooth 
implementation of teaching activities. For instance, as for preparation of plays of Chu opera in textbooks, teachers shall start from the simple plays to the difficult plays to realize step-by-step progress and make sure that the students can learn Chu opera in a more comprehensive and systematic way, During learning of Chu opera, students can get a deeper understanding of inheritance and development of local folk music. Hence, it is good for cultivation of more professional talents who will make contributions to sustainable development of art of music.

4.3 To innovate teaching methods

In the information ear, modern teaching technologies have become an integral part of music teaching in universities. For this reason, we can adopt multimedia technologies in integration of Chu opera and music teaching in universities, such as, watching video and listening to audio materials to help students obtain more knowledge of Chu opera. In addition, teachers can arouse the enthusiasm of students by organizing discussion on living habits and characteristics of minorities and learn some folk songs and dances[4]. What's more, compared with basic teaching stage, college students are more mature with stronger subjective initiative and are capable of organizing some social practices independently, such as founding Chu opera club to attract the students interested in Chu opera to learn some basic ways of performance. Thus students can feel the charm of traditional Chinese folk music by daily immersion. In addition, social activities can also be organized to spread Chu opera among the masses. As we all known, art comes from life. Hence,for the purpose of further understanding of Chu opera teachers can organize students to collect folk songs and participate in life of local residents to know about development history and characteristics of Chu opera and put their unique insights into the understanding. Thus, the students can know better about Chu opera and get a deeper impression of the performance skills. With those measures, the music teaching system for universities can be gradually improved.

\subsection{To fully respect students' subjectivity}

In recent years, practical activities in music teaching in universities have made substantial progress and a great many universities have set up music specialty. Under the quality education system, teachers need to lay emphasis on difference in volume between the parts and timbre in chorusing while teaching basic intonation and rhythm to students in practical teaching. Each student has his or her own unique voice, thus, teachers shall fully respect students' subjectivity and guide them to listen to melody of other parts and train their multi-tone hearing ability to according to features of students' voice. In performance of Chu opera, students shall carefully observe the interpretation of music by different characters so as to enhance music perception[5]. As is well-known, music for voice in Chu opera can be incisively reflected by performance of the actors. That means, without innovation of the actors, any music for voice no matter how beautiful it is, cannot reach the expected objectives. As such, the top priority of the combination of Chu opera and music teaching in universities lies in cultivation of professional talents. Only if we nurture more music talents, can we successfully enable them to show their initiative and enthusiasm in work and make more contribution to inheriting and carrying forward Chu opera. With the advancement of traditional culture, universities shall launch further studies for the purpose of innovation of Chu opera.

\section{Conclusions}

As discussed above, Chu opera is an important part of Chinese traditional music culture and the specific embodiment of folk culture

Progress. Universities are the main carriers for inheriting ans carrying forward traditional culture, it can not only enrich content of teaching but also promote innovation of traditional culture cultural by integration of Chu opera and music teaching. Therefore, in teaching practices, teachers shall discard the old-fashioned teaching principle and fully understand significance of traditional music education in accordance with the learning needs of students at the present time. Meanwhile, teachers shall probe into value of music culture of Chu opera, widely collect music materials, and prepare music textbooks to support orderly implementation of teaching activities. Moreover, they shall 
introduce multimedia technologies and adopt diversified teaching methods to build a harmonious teaching atmosphere and continuously enhance teaching quality so as to accelerate sustainable development of local music culture in China.

\section{Acknowledgements}

This work was supported by the key subject of 2015 in hubei province education scientific planning chu opera into the moment of its strategy research of college music class"(project numbe: 2015GA060).

\section{References}

[1] Yang Minghui, A Brief Discussion on Music Innovation and Development in the Chu Opera Chasing for Statements [J], Great Stage, 2010 (05):61;

[2] Cai Jizhou, Sustainable Development of Chu Opera [J], Home Drama (First Semimonthly), 2010, (08):57-60;

[3] Liu Lin, A Comparative Study on Music Creation of Two Chu Operas [D], Wuhan Conservatory Of Music, 2007;

[4] Rao Pingxiang, Kang Qingfang, Several Thoughts on Reform of Music Reform of Chu Opera [J], Today’s Mass Media, 2015 (08):117-118;

[5]Luo Mulei, Phoenix Dancing after Nirvana \& Bosom Friend by Buddhism, -- Recall on Peak Season of Creation of Operatic Vocal Music in Chu Opera [J],Home Drama (First Semimonthly), 2012, (07):11-13+31. 